\title{
PESQUISA EM EDUCAÇÃO COMPARADA SOB CONDIÇÕES DE INTERCONECTIVIDADE GLOBAL ${ }^{1}$
}

COMPARED EDUCATION RESEARCH UNDER GLOBAL INTERCONNECTIVITY CONDITIONS

INVESTIGACIÓN EN EDUCACIÓN COMPARADA BAJO CONDICIONES DE INTERCONECTIVIDAD GLOBAL

\author{
SOUZA, Claudia Schiedeck Soares de ${ }^{2}$ (D) \\ STRECK, Danilo Romeu3 ${ }^{3}$
}

Em sua breve passagem pela Universidade do Vale do Rio dos Sinos como professor visitante pelo CNPq, no mês de março de 2018, o professor Dr. Jürgen Schriewer ${ }^{4}$ realizou um seminário e algumas palestras sobre a temática da Educação Comparada, além de conceder também uma entrevista acerca de aspectos que marcaram sua carreira como pesquisador em diferentes universidades da Alemanha. Num desses momentos, contou sobre como ele e a família cruzaram, em 1948, a linha de demarcação estabelecida pelos aliados após derrotar a Alemanha nazista. O objetivo da expedição, conforme relato do próprio Schriewer, era poder finalmente encontrar o pai que se encontrava detido num campo de prisioneiros americano. Em suas próprias palavras esse limite "não era uma fronteira verdadeira, mas um marco imaginário5." Ainda não havia, naquele momento, uma divisão geográfica que delimitasse o espaço físico entre o lado ocidental e oriental alemão, como mais tarde o Muro de Berlim tão tristemente o fez, mas apenas uma predisposição abstrata em dividir espacialmente o lado vencedor e o vencido.

Ler os capítulos que compõem do primeiro livro de Jürgen Schriewer publicado no Brasil, "Pesquisa em Educação Comparada sob Condições de Interconectividade Global", é como cruzar, também, uma linha de demarcação, exatamente como ele tão bem descreveu. Temos a sensação de sair de um espaço conceitual muitas vezes fluido e pouco preciso do campo de estudo da Ciência

\footnotetext{
${ }^{1}$ SCHRIEWER, J. Pesquisa em educação comparada sob condições de interconectividade global. Tradução de Geraldo Korndöfer e Luis Marcos Sander. São Leopoldo: Oikos, 2018.

2 Universidade do Vale dos Sinos - Unisinos - São Leopoldo - Rio Grande Sul - Brasil

3 Universidade do Vale dos Sinos - Unisinos - São Leopoldo - Rio Grande Sul - Brasil

4 Jürgen Schriewer iniciou sua carreira acadêmica como professor da Universidade de Frankfurt (1975 a 1991). Após a queda do Muro de Berlim, foi convidado a ajudar na reconstrução da Universidade Humboldt, em Berlim, onde também coordenou o Centro de Educação Comparada da universidade, talvez o mais renomado centro de pesquisa educacional comparativa na Europa Continental. Ocupou diversas posições destacadas no campo da educação comparada, incluindo a Presidência da Sociedade de Educação Comparada da Europa (1992-1996), a Presidência do Comitê Permanente de Pesquisa do Conselho Mundial de Educação Comparada (1996-2002), além de ter tido uma carreira profícua como professor visitante em grandes universidades como a Universidade de Paris V-René Descartes, a Universidade de Estocolmo, a Universidade de Waseda no Japão, a Universidade Nacional Autônoma do México e a Universidade de San Andrés em Buenos Aires. Apesar de uma vasta publicação na área, em diversos idiomas, nenhuma delas havia sido realizada no Brasil.

${ }^{5}$ Os aliados, ao derrotar a Alemanha Nazista, dividiram o território em quatro áreas de ocupação para finalidades administrativas e a linha de demarcação entre os setores de ocupação ocidental e o soviético foi acordado em um protocolo estabelecido na Conferência de Teerã (1943).
} 
Comparada para encontrar nas suas páginas um percurso seguro e balizado claramente pela abordagem histórica e sociológica. Não existe, neste percurso, um momento determinado ou específico onde se possa dizer que essa travessia ocorra. Ela apenas decorre da leitura atenta de cada passagem, da reflexão profunda de cada marco conceitual e do estabelecimento de relações entre eles, o que nos permite organizar um construto sólido e vigoroso sobre os estudos comparativos, sua origem e desafios futuros.

O autor apresenta ao longo do livro uma proposta de abordagem para os estudos comparativos, acentuando as dimensões necessárias para que o leitor a compreenda. Num primeiro momento, apresenta a perspectiva histórica que deve sustentar qualquer posição epistemológica sobre a Educação Comparada, para então, num segundo momento, traduzir os matizes que a compõem, definindo claramente os paradigmas e caminhos metodológicos estabelecidos na trajetória desse campo de conhecimento. Somam-se a esses elementos, as imprescindíveis abordagens científicas para o desenvolvimento de pesquisas comparativas coesas, as quais se contrapõem àquelas desenvolvidas com o intuito de estabelecer o que Schriewer chama de sociedades de referência internacional, com base teórica informal e de caráter reformista.

Já no primeiro capítulo, "Educação Comparada - um campo proteico", nos deparamos com as reflexões do autor sobre a identidade desse campo de estudo e sua proposição de resgatar os dilemas que perpassam as múltiplas áreas dos estudos comparativos e internacionais na educação, principalmente no que se referem às concepções inerentes ao seu surgimento, ou seja, sua identificação como objeto de pesquisa:

Depois de conceitualizar e rejeitar quase uma dúzia de possíveis esforços para tal exposição ao longo dos últimos anos, proponho que a "Educação Comparada" não pode mais ser concebida em termos de uma coerência imaginária da área - e muito menos de uma consistência - mas, antes, em termos de ramos distintos de estudos comparativos e internacionais em educação e das problemáticas subjacentes deles. (SCHRIEWER, 2018, p. 13).

Ao propor que a Educação Comparada seja debatida não a partir das suas limitações ou dogmas, mas fundamentada na história, na antropologia e sociologia do conhecimento, Schriewer (2018) distingue estruturalmente três perspectivas distintas que, de certa forma, subjazem as pesquisas comparativas da educação. Primeiramente, aponta para estudos que se destacam pela sua dimensão epistemo-lógica, onde repousa a pesquisa social comparada propriamente dita, e nos quais encontramos parâmetros relevantes para o seu desenvolvimento, entre eles, o estabelecimento de uma questão orientadora dentro de um marco teórico já estabelecido, o discernimento em relação à diversidade sociocultural, o compromisso com o "distanciamento" e o "perspectivismo" e a necessidade de se estabelecer inter-relações conceituais. A combinação desses elementos permitiria uma análise criteriosa desses estudos tendo como objetivo construir uma concepção teórica sustentada em bases consolidadas sócio-historicamente.

O segundo enfoque que se percebe em outra linha de análises comparativas é o da sócio-logica, que se deriva de pesquisas estruturadas em relatórios sem grande sustentação teórica e que estabelecem relações entre situações concretas, cujos resultados apontam, sobremaneira, para 
orientações e recomendações reformistas e intervencionistas apoiadas em um receituário internacional. Basicamente, são estudos determinados pela urgência na implementação de políticas educacionais e caracterizados por padrões descritivos e que carecem de reflexividade.

Por último, Schriewer destaca um outro corpus de investigações da Educação Comparada permeado pela dimensão da globo-lógica que se fundamenta na discussão sobre um sistema mundial interligado e unificado, a forma com que ele opera externamente aos estados e às organizações e como interfere na construção de políticas públicas para a educação. Para ele, essa perspectiva se insere na constituição do campo de estudos da Educação Comparada desde o momento histórico em que o estado-nação moderno se estabelece definitivamente balizado pela conjuntura que cerca essas relações internacionais entre os países. É assim, que quase ao final do século $\mathrm{XX}$, a temática internacional assume preponderância como um dos sentidos possíveis para a comparação educacional, ainda mais sob impacto do aumento da mobilidade entre países e do advento da ubiquidade tecnológica.

Estabelecidos dessa forma os fundamentos de como a Educação Comparada se desenvolveu nos marcos teóricos sociológicos, Jürgen Schriewer, nos capítulos seguintes, aprofunda alguns dos conceitos já apresentados e detalha sua compreensão sobre os pressupostos que devem estar manifestos em uma abordagem comparativa cuidadosa.

Em "Ciência Social Comparada - problemas característicos e soluções cambiantes", o autor nos apresenta um resgate histórico da arena por onde os estudos comparativos foram se desenvolvendo, iniciando pela antropologia comparada de Humboldt (1795) e chegando, mais tarde, nos primórdios desse campo educacional, com Jullien de Paris (1817). Nesse período, quando as bases científicas da abordagem comparativa se estabelecem e se associam aos modelos científicos da época, a comparabilidade começa a se configurar como sistematização de dados produzidos pela observação e medição ordenadas. É também nesse momento que se estruturam as questões centrais que vão permear o desenvolvimento da ciência comparativa, ou seja, a sua transformação em método investigativo e, consequentemente, a expressão de uma natureza mais sofisticada no estabelecimento de relações, a elaboração de uma abordagem problematizadora a partir dos contextos culturais e, por fim, o caráter experimental de análise dos dados coletados. Ao final desse capítulo, Schriewer (2018) nos propõe uma estrutura analítica para auxiliar nas estratégias de pesquisas comparativas, levando em conta a efetividade e suposições subjacentes a elas.

A questão central tratada pelo pesquisador no capítulo "Rumo a uma ciência da complexidade" diz respeito à pretensão essencial desse campo de estudos em oferecer respostas possíveis para eventos macrossociais. Para trazer à tona a complexidade de tal desafio, ele explicita as tensões e dificuldades presentes no desenvolvimento metodológico dos marcos teóricos que acompanharam as ciências sociais e humanas comparadas, resgatando seu vínculo inicial com a ciência experimental e, posteriormente, ao final do século $X X$, sua associação com os estudos dos sistemas evolutivos complexos, trazendo reflexões fundamentais sobre as abordagens "nomotéticas" e os "sistemas sociais autorreferenciais". 
Na sequência, no capítulo 4, "O método comparativo e a necessidade de externalização: critérios metodológicos e conceitos sociológicos", o autor esclarece aos leitores sobre a lacuna existente entre estudos comparativos realizados por meio de uma abordagem metodológica consistente e aqueles carentes de sistematização e de construções inter-relacionais, reforçando a conveniência de se discutir a identidade desse campo de estudo e propondo um marco conceitual para a Educação comparada. Para isso, Schriewer conceitua as diferentes perspectivas analíticas que se estruturam nesse campo de estudo, destacando: a) os tipos de comparação existentes (por um lado a "operação mental universal", onde se percebem conexões entre casos manifestos, e por outro o imperativo das interrelações como base conceitual); b) as disposições mentais de cada modelo, as quais envolvem a necessidade do "perspectivismo" e "distanciamento", como ponto de vista indispensável para o observador na construção de análises consistentes, na contraposição ao "sociocentrismo" e o "envolvimento"; e, c) os contextos sociais de referência e o caráter teórico de cada um. Como base de sua argumentação, o autor se utiliza da Teoria dos Sistemas Sociais de Luhmann para desenvolver as diferenciações entre duas concepções e explicita:

\begin{abstract}
A linha de raciocínio desenvolvida até aqui leva, portanto, a conceber a Educação Comparada não mais em termos de uma identidade disciplinar que pretende ser definível do ponto de vista da filosofia da ciência, mas é constantemente questionada pelos desdobramentos factuais Antes, a conclusão é que se deve reconsiderar o campo em termos de uma duplicação de estilos teóricos, tal como se supõe no modelo de diferenciação de sistemas. "A duplicação de sistemas teóricos", nesse caso, denota a diferença que existe entre uma Ciência da Educação Comparada referente à função do subsistema social para a pesquisa científica, e uma Reflexão Reformativa Internacional sobre a educação que se cristaliza a partir das autointerpretações do sistema educacional e responde às suas expectativas de orientação. (SCHRIEWER, 2018, p. 158-159)
\end{abstract}

Ainda importante destacar que nesse capítulo, Schriewer apresenta o conceito de "externalização" vinculado à Educação. Ao questionar "qual pode ser a funcionalidade de um conhecimento de alteridade cultural que não resulta em conclusões garantidas por regras metodológicas de inferência"? (SCHRIEWER, 2018, p. 160), o pesquisador aponta que a resposta não pode ser encontrada unicamente na racionalidade científica, mas também no rompimento com a circularidade analítica de processos autorreflexivos que traduzem apenas aspectos descritivos próprios. Essa ruptura se configura em uma espécie de legitimação para que um sistema se exponha a concepções exteriores, mesmo que de forma seletiva, trazendo para a reflexão um "sentido suplementar".

No campo da Educação, que é equivalente à autorreflexão do sistema educacional, Luhmann e Schorr identificaram três modelos de externalização dominantes, embora possivelmente não excludentes. Uma forma de externalização faz referência a pressupostos que pretendem garantir a natureza cientifica dessa disciplina, outra faz referência a valores e a terceira à organização. As respectivas funções cumpridas por estas formas de externalização, segundo Luhmann e Schorr, consistem em estabilizar a Educação enquanto corpus particular de conhecimento teórico organizado como uma disciplina acadêmica e, ao, mesmo tempo assegurar a esse campo uma autonomia máxima na construção da teoria pedagógica. (SCHRIEWER, 2018, p. 161).

O capítulo 5, "Construções da internacionalidade na educação", escrito em parceria com Carlos Martinez, discute os conceitos de internacionalização e/ou globalização da educação contrapondo-se à 
perspectiva teórica neoinstitucionalista ${ }^{6}$, que, a partir de dados empíricos, apresenta posições que tentam comprovar a existência de uma orientação institucionalizada em nível mundial para a área educacional referente aos currículos, à organização e à expansão da educação. Os autores refutam essas evidências apoiando-se no conceito de externalização que, enquanto postura crítica inerente às instituições de um estado pode não permitir uma análise mais exata de como os processos de incorporação e representação de modelos internacionais educacionais ocorrem, pois seleciona, admite e incorpora paradigmas propostos internacionalmente a partir de suas próprias reflexões sistêmicas internas, permitindo a esses sistemas absorver e integrar sentidos adicionais e complementares advindos de suas próprias experiências. E, em sendo assim, a concepção de um sistema único educacional difundido e padronizado globalmente é mediado por diferenças culturais de cada estadonação, assim como é incorporado em suas acepções pela institucionalidade e seus atores principais, sejam eles teóricos, docentes, gestores, formuladores de políticas, entre outros. Para exemplificar suas posições teóricas, Schriewer e Martinez apresentam um estudo comparativo sobre as referências à literatura educacional internacional em diferentes países (Espanha, Rússia e China). Com o objetivo de reavaliar as pressuposições estabelecidas pelos teóricos neo-institucionalistas sobre a perspectiva de uma padronização educacional mundial, os autores selecionaram como unidades de análise periódicos científicos de países com distintas organizações ideológicas e diferentes culturas civilizacionais. A premissa inicial desse trabalho era a de que, embora se pudesse observar uma certa homogeneização da organização educacional em nível global, esses processos estão vinculados intrinsicamente ao desenvolvimento específico de suas culturas. Para tanto, foram selecionadas revistas da área da educação, com temática geral, aceitas como publicações científicas em seu contexto e que, na maioria das vezes, eram publicadas por organizações estatais. Os critérios utilizados para a validação dessa hipótese verificaram a influência de conceitos ou enunciados que admitiam conhecimentos internacionais, e os resultados sinalizaram justamente como o impacto das mudanças sociais e políticas em cada uma dessas sociedades manifestam diferentes interpretações de políticas de reformas e modelos educacionais transnacionais.

Apresentado como parte de uma palestra realizada na 39॰ Conferência Anual da Sociedade de Educação Comparada e Internacional realizada em Boston, Massachusetts, o Capítulo 6, "Sistemamundo e redes de inter-relação", inicia trazendo um breve histórico dos conceitos de internacionalização e globalização, em especial quanto à ambiguidade com que esses termos se estabeleceram no campo da educação comparada e/ou educação internacional na tentativa de validar construtos teóricos que discutem os sistemas e a teoria educacional. Assim, o autor resgata historicamente a gênese da comparação nas ciências sociais, partindo dos primórdios do método comparativo no início do século XIX, e já abordado por ele no Capítulo 2, até chegar ao conceito do mundo como fragmento de análise, onde incorpora à discussão teórica autores como Durkheim (2003), Luhmann (2016) e Bergesen (1980). Ao final dessa reflexão, Schriewer nos aponta alguns dos

\footnotetext{
${ }^{6}$ Para a melhor compreensão do conceito sugere-se a leitura de HALL, P. e TAYLOR, R. As três versões do neoinstitucionalismo. Disponível em: http://www.scielo.br/pdf/ln/n58/a10n58.pdf
} 
caminhos a serem trilhados por esse campo de pesquisa, em particular, uma aproximação entre a comparação e a história, tendo em vista que

\begin{abstract}
Esse marco teórico torna possível, portanto, uma conceitualização da pesquisa históricocomparada que é suficientemente complexa para permitir a análise dos supostos "universais evolutivos" - não no abstrato, mas como universais historicamente concretos, isto é, inseridos em processo de diferenciação social, de interação social e de difusão global. (SCHRIEWER, 2018, p. 244).
\end{abstract}

Em seus dois últimos capítulos, o livro nos apresenta análises críticas sobre as "construções de internacionalidade" que levam a uma reflexão mais intensa sobre os conceitos de sociedade ou cultura mundial. Para isso, Schriewer discorre sobre o Processo de Bolonha7 no Capítulo 7 ("Bolonha - um "mito" neoeuropeu?"), explicando a partir das concepções neo-institucionalistas seu surgimento enquanto modelo e sua propagação nos países e instituições europeias. Nas duas primeiras partes do texto, Schriewer retoma historicamente a constituição do acordo que padronizou o ensino superior na Europa, tendo como pano de fundo a difusão e reiteração da proposta como forma de sua consolidação nos meios acadêmicos. Contudo, o autor ressalta que, embora não se tenha tido tempo suficiente para analisar mais profundamente a implantação dessa proposta, já é possível perceber que existe uma lacuna considerável entre a ratificação política de seus princípios gerais e a aplicação prática dos mesmos nas instituições educacionais, questão que ele aborda na terça parte do texto. Nesse sentido, os dados empíricos demonstram que estratégias de recontextualização e interação acabam por subverter atos normativos top-down ${ }^{8}$ exarados pelas autoridades políticas dos países do bloco, quer seja pela autonomia institucional e estatal já estabelecidas pela tradição, quer seja pelas disposições constitucionais e jurídicas instaladas nos países de origem, quer seja pelos significados culturais presentes nos valores, nas organizações e padrões interpretativos de cada um deles, o que de certa forma valida a posição já explicitada pelo autor nos capítulos anteriores sobre a ideologia neoinstitucionalista de sistema mundial educacional.

Em "Memória, sentido e constelações de sentido: a compreensão da cultura mundial como cultura contextualizada" (capítulo 8), último dos artigos do livro, vemos retratado como a abordagem neoinstitucionalista vem se construindo enquanto vanguarda teórica dentro do campo de estudos da pesquisa comparativa, embora a força probatória das evidências colhidas pelas pesquisas sociais e educacionais contradigam esse pensamento. Não se pode negar, por óbvio, uma tendência transnacional de padrões, normas e políticas educacionais, principalmente com finalidades reformistas.

\footnotetext{
7 Processo iniciado a partir da Declaração de Bolonha, acordo assinado pelos os ministros da Educação de diversos países de Europa em 1999 (tanto da União Europeia como de outros países como Rússia ou Turquia), na cidade italiana de Bolonha. Trata-se da convergência educacional para que facilitar o intercâmbio de graduados e adaptar o conteúdo dos estudos universitários às demandas sociais, melhorando a sua qualidade e competitividade através de uma maior transparência e uma aprendizagem baseada no estudante quantificada através dos créditos ECTS. Polêmico, seus críticos apontam para as características privatistas e mercadológicas de suas premissas.

${ }^{8}$ Abordagem administrativa que prevê que os processos de tomada de decisão sejam realizados somente no âmbito da alta cúpula da gestão, sendo então encaminhadas para o cumprimento nas demais áreas ou subníveis, ou seja, compete aos setores inferiores da administração executarem o que foi determinado.
} 
Contudo, ao se inter-relacionar com as diferenças culturais, constitucionais, organizativas de cada sociedade ou instituição, esses modelos acabam sendo recontextualizados e multifacetados, o que o autor aponta como um processo de recriação de sentido. Contrapondo-se aos argumentos apresentados pelos defensores da "sociedade mundial", Schriewer relaciona os conceitos neoinstitucionais e vai expondo suas contradições. Para a concepção do mundo moderno como "universo simbólico" estruturado em normatizações e padrões, o autor propõe uma abordagem do mundo como uma "arena aberta para múltiplos atores", que através de recursos de criação de padrões diferenciais permitem aos estados e suas instituições um desenvolvimento próprio. Em contraste com a tese do "acoplamento frouxo", isto é, o hiato existente entre as potenciais organizações que dão suporte à disseminação de padrões educacionais, o autor propõe os "mecanismos de recontextualização seletiva", que para ele devem dar conta não somente da descrição desses fenômenos, mas também da elucidação dos múltiplos fatores distintos envolvidos nos mesmos. E, por último, ao contestar a ideia do "ator roteirizado", cujo papel seria definido por uma estrutura cultural universalizada, o pesquisador alemão nos propõe a pressuposição de "processos contestados de produção de sentido", o que traz o ator para a construção permanente e múltipla de novas condições e desafios, que, definitivamente, levam em consideração tanto padrões mundiais quanto perspectivas constituídas pela história, pela cultura e pelo contexto.

Enfim, Jürgen Schriewer nos conduz, em todos os seus textos, pelo caminho do esclarecimento e da rigidez conceitual e propõe que a pesquisa comparada não siga o trajeto mais curto para sermos pragmáticos. Ao contrário, nos aponta a necessidade de abrir novas perspectivas de compreensão e desenvolvimento para a Educação Comparada, ampliando a profundidade teórica necessária para estudos comparativos consistentes. No Brasil, a temática ainda é bastante incipiente, quer seja pela tendência que encontramos na pesquisa educacional do país de não olharmos além das nossas fronteiras, quer seja pela ausência de literatura produzida sobre o assunto. Ao lermos "Pesquisa em educação comparada sob condições de conectividade" encontramos o texto de um pesquisador que teve sua trajetória acadêmica e pessoal marcada pela história, cultura e tradição de seu país e que se serviu delas para oferecer a outros pesquisadores uma concepção única sobre a Educação Comparada. Ao enfatizar ao longo do livro que a pesquisa em educação comparada se dedica sobretudo a analisar "relação entre relações", Schriewer nos desafia a evitar comparações apressadas e simplistas. Nas palavras do autor,

Estes são modelos e perspectivas analíticas que têm a capacidade de enriquecer consideravelmente nosso conhecimento dos mecanismos que engendram as intrincadas complexidades, incluindo a simultaneidade de correntes e fenômenos contrários, que caracterizam a sociedade mundial hoje. (SCHRIEWER, 2018, p. 298).

Quando de sua passagem pelo Brasil, em março de 2018, Jürgen Schriewer compartilhou com alunos, pesquisadores e professores da UNISINOS seus conceitos, suas reflexões e suas provocações, fruto de uma vida dedicada aos estudos da educação comparada. Quem se interessar, 
poderá complementar a leitura do livro com as palestras disponíveis no canal do Centro de Estudos Internacionais em Educação da Unisinos ${ }^{9}$. A internacionalização na educação é hoje um imperativo e a construção de um quadro de referência consistente nos ajudará a interagir de forma crítica com propostas pedagógicas e políticas educacionais de outras regiões do mundo. Aos leitores desejamos que o prazer do aprendizado teórico sobre a Educação Comparada seja proporcional ao prazer da leitura do livro de Jürgen Schriewer.

\section{REFERÊNCIAS}

1. BERGESEN, A. Studies of the Modern World System. New York: Academic Press, 1980.

2. DURKHEIM, E. As regras do método sociológico. São Paulo: Martin Claret, 2003.

3. HUMBOLT, W.Von. Plan einer vergleichenden Anthropologie. In: Wilhem von Humboldt, Werke in fünf Bänden. Stuttgart: Cotta'sche Buchhandlung, 1975. v.1, p.337-375.

4. JULLIEN DE PARIS, M.-A. Esquisse et vues préliminaires d'un ouvrage sur l'éducation comparée entrepris d'abord pour les vingt-deux cantons de la Suisse et pour quelques parties de l'Allemagne; susceptible d'être exécuté plus tard, d'après le même plan, pour tous les États d'Europe. Paris: L. Colas, 1817.

5. LUHMANN, N. Sistemas Sociais: esboço de uma teoria geral. São Paulo: Vozes, 2016.

\section{Claudia Schiedeck Soares de Souza}

Professora de Magistério Federal no IFRS e doutoranda no programa de pós-graduação de Educação da Unisinos.

\section{Danilo Romeu Streck}

Doutor em Educação e Professor do Programa de Pós-Graduação em Educação da Universidade do Vale do Rio dos Sinos.

\footnotetext{
${ }^{9}$ Link: https://www.youtube.com/channel/UCHLz4UPN4S8Q6spCNgo3zww?spfreload=10. 


\section{Como citar este documento:}

SOUZA, Claudia Schiedeck Soares de; STRECK, Danilo Romeu. Pesquisa em educaçao comparada sob condições de interconectividade global. Reflexão e Ação, Santa Cruz do Sul, v. 27, n. 3, p. 260-268, out. 2019. ISSN 1982-9949. Disponível em: <https://online.unisc.br/seer/index.php/reflex/article/view/12480>. Acesso em: . doi:https://doi.org/10.17058/rea.v27i3.12480. 